\title{
Aerodynamic Properties of Tef for Separation from Chaff
}

\author{
Abayineh Awgichew \\ Oromia Agricultural Research Institute, Asella Agricultural Engineering Research Center, Ethiopia
}

\begin{abstract}
The knowledge of the aerodynamic characteristics of tef grains and chaff (floating velocity, aerodynamic resistance coefficient) is significant for the construction and operation of machines, which treat substances with air flow and in all cases when substances are moved in the air. Terminal velocity and drag coefficient of tef grain and straw materials (Kuncho variety) have been experimentally measured by suspending the particles in an air stream. The effects of moisture content of tef grain, node position and length of straw on terminal velocity were studied. The results showed that moisture content have significant effects $(\mathrm{p}<0.01)$ on terminal velocity. By increasing moisture content from 7.3 to $25.94 \%$ (w.b.), its terminal velocity increased linearly from 2.98 to $3.87 \mathrm{~m} / \mathrm{s}$. Drag coefficient of the tef grain decrease from 0.77 to 0.59 as moisture content increase from 7.3 to $25.94 \%$. The terminal velocity of the straws with different node positions (node free, end node, and middle node) and lengths (1 to $10 \mathrm{~cm}$ ) were also measured.
\end{abstract}

Keywords: Aerodynamic properties, terminal velocity, drag coefficient, tef, straw, node

DOI: $10.7176 / \mathrm{CER} / 11-3-05$

Publication date: April $30^{\text {th }} 2019$

\section{Introduction}

One of the economical cereal crops in Ethiopia is tef. It is indigenous to the country, and is a fundamental part of the culture, tradition, and food security of the people. This crop is gaining international recognition and acceptance, and is a means of foreign currency earning in addition to its value as food and industrial crop at home. Currently, tef is grown on approximately 2.80 million hectares of land which is $27 \%$ of the land area under cereal production. Tef accounts for about a quarter of the total cereal production and is highly economical food grain in Ethiopia. Approximately, 6 million households grow tef and it is the dominant cereal crop in 30 of the 83 high-potential agricultural woredas (Bekabil et al., 2011). The grain, after grinding and fermentation of the dough, is used to make a thin flat pan cake called "injera" (Eleni, 2001).

Tef Grain cleaning can be considered a stochastic process with particles changing orientation in a random manner both in time and space. Separation and cleaning is conventionally achieved as a result of the differences in the size, density and terminal velocity of the mixed product. The cleaning process is a mass transfer process involving segregation of particles on a pan before coming to the air stream, motion in the air stream and motion after coming out of the air stream (Simonyan etal, 2006). Impurities and contaminants are separated from sound grains during cleaning process. Clean grains save storage space and increase marketability. Contaminants affect the quality of grains and make grains less attractive in appearance therefore they constitute easy habitants for pests, increase handling cost, and ultimately cause low market value.

Agricultural engineers have used separation and handling of material by compressed air for many years. Knowledge about aerodynamic properties of agricultural materials is a necessity for hydrodynamic and aerodynamic behavior of material. Drag coefficient and terminal velocities of material are the most important parameters in aerodynamic. Terminal velocity is one of the most important parameters for separation of (MOG) chaff and tef (grain) from each other. Terminal velocity for each element of agricultural materials for separation and handling is very important and therefore, is a very effective parameter for agricultural machine and system design (Rabani et al., 2002; Tabatabaeefar, 2003). Pneumatic separation and cleaning is most widely used method because air is chiefly available, of the lowest cost and it doesn't cause any mechanical damage during separation and cleaning operations of materials.

Mohsenin (1978) indicate that separation of a product from its associated and yet undesirable materials, such as straw and chaff, in air stream, require knowledge of aerodynamic characteristics of all the particles involved. Furthermore, it was noted that a range of air velocities, for effective separation of the grain from MOG need to be estimated. As such, the terminal velocity $(\mathrm{Vt})$ be used as an important aerodynamic characteristic of materials in pneumatic conveying and separation. Wu et al. (1999) and Ayman, 2009 noted that by defining the terminal velocity of different threshed materials, it was possible to determine and set the maximum possible air velocity in which MOG can be removed without losses.

\section{Materials and Methods}

\subsection{Sample preparation}

The tef, namely, KUNCHO (

amharic) was used in the experiments. The cultivars were procured from the Ethiopian clean seed enterprise Asella branch. The moisture content of the seeds was determined by the standard oven drying method at $105^{\circ} \mathrm{C}$ for $24 \mathrm{~h}$ (Zewdu and solomon, 2007; Dursun \& Dursun, 2005; Balasubramanian, 
2001). The initial moisture content of the tef grain was found and in order to be able to measure the effect of moisture content on terminal velocity, the grain was rewetted by adding a calculated amount of water according to equation 1.

$$
Q=\frac{W\left(M_{f}-M_{i}\right)}{\left(10 o-M_{f}\right)}
$$

The straws had a length of 1 to $10 \mathrm{~cm}$ with three different node position groups: node free, middle node and end node. The means of mass (M) and diameter (D) of the straw samples were given in Table1.

Table 1. Specification of Tef Straw Samples

\begin{tabular}{lllcccc}
\hline $\begin{array}{l}\text { Straw Length } \\
(\mathrm{cm})\end{array}$ & \multicolumn{2}{c}{ Node Free } & \multicolumn{2}{c}{ Middle Node } & \multicolumn{2}{c}{ End Node } \\
& $\mathrm{M}(\mathrm{g})$ & $\mathrm{D}(\mathrm{mm})$ & $\mathrm{M}(\mathrm{g})$ & $\mathrm{D}(\mathrm{mm})$ & $\mathrm{M}(\mathrm{g})$ & $\mathrm{D}(\mathrm{mm})$ \\
\hline 1 & 0.010 & 2.35 & 0.022 & 1.59 & 0.013 & 1.58 \\
2 & 0.014 & 2.26 & 0.023 & 1.50 & 0.015 & 1.73 \\
4 & 0.024 & 1.63 & 0.027 & 1.78 & 0.026 & 1.61 \\
6 & 0.026 & 1.54 & 0.032 & 1.80 & 0.031 & 1.67 \\
8 & 0.033 & 1.68 & 0.057 & 1.7 & 0.060 & 1.74 \\
10 & 0.059 & 1.62 & 0.351 & 1.87 & 0.057 & 1.72 \\
\hline
\end{tabular}

$\mathrm{M}=\operatorname{mass}(\mathrm{g}) \quad \mathrm{D}=\operatorname{diameter}(\mathrm{mm})$

\subsection{Terminal velocities and Drag coefficient Measurement}

Determination of terminal velocity of tef seed is not possible by predicting them from mathematical relationships like most agricultural products that are not spherical so it is better to measure terminal velocities experimentally in the laboratory (Zewdu, 2007). The terminal velocity was determined using an air column. The measurement device consisted of three components. A vertical tube, a fan connected to a speed control and a hot wire digital anemometer with a probe. In order to homogenize the air flow and reduce the turbulence an air flow straightener made of Teflon was placed in the vertical tube. A wire grid was positioned in the vertical tube to prevent the sample from falling down to the bottom. For each test, a small sample dropped into the air stream in the vertical tube and air was blown by a fan in the upward direction. Then the air flow rate was increased by the speed control unit until the sample was suspended in the vertical air stream. The probe of the hot wire anemometer was inserted into the air stream through a small hole in the wall of the tube and the air velocity near the location of the seed suspension was measured to an accuracy of $0.01 \mathrm{~m} / \mathrm{s}$ (Kara etal, 2012).

When a particle is suspended in a vertical airflow, then the speed of the airflow holding this position is called the terminal velocity $(\mathrm{Vt})$ of the particle and the drag force is balance by the particle weight $(\mathrm{mg})$, such that

$$
\begin{aligned}
& M g=\frac{1}{2} C d \rho a A V_{t}^{2} \\
& V_{t}=\left(\frac{2 M g}{C d \rho a A}\right)^{1 / 2} \\
& C d=\frac{2 M g}{V_{t}^{2} \rho a A}
\end{aligned}
$$

Where $\mathrm{M}$ is the mass of the particle $(\mathrm{kg}), \mathrm{g}$ is the acceleration due to gravity $\left(9.81 \mathrm{~m} / \mathrm{s}^{2}\right), \mathrm{Vt}$ is the air terminal velocity $(\mathrm{m} / \mathrm{s}), \mathrm{Cd}$ is the coefficient of drag, $\rho a$ is the air density $(1.25 \mathrm{~kg} / \mathrm{m} 3)$ and $\mathrm{A}$ is the particle area projected to air, $\mathrm{m}^{2}$. The terminal velocity $(\mathrm{Vt})$, thus, depends on the mass of particle $(\mathrm{M})$, its projected area $(\mathrm{A})$ and the coefficient of drag $(\mathrm{Cd})$ among other constant factors ( $\mathrm{g}$ and $\rho$ ). The coefficient of drag $(\mathrm{Cd})$ varies according to other factors including geometry and surface of particle, and state of airflow around it (Gorial and O'Callaghan 1990; Tabak and Wolf 1998).

\section{Results and Discussion}

\subsection{Effect of moisture content on Terminal Velocity and Drag Coefficient}

Terminal velocity and drag coefficient were linearly related to moisture content as indicated in equations Table 1. Table 1. Linear equation for terminal velocity and drag coefficient

\begin{tabular}{ccc}
\hline Parameter & \multicolumn{1}{c}{ Equation } & $\mathbf{R}^{\mathbf{2}}$ \\
\hline $\mathrm{Vt}, \mathrm{MC}$, & $\mathrm{Vt}=0.0472 \mathrm{MC}+2.6624$ & 0.9866 \\
$\mathrm{C}_{\mathrm{d}}, \mathrm{MC}$ & $\mathrm{C}_{\mathrm{d}}=-0.01 \mathrm{MC}+0.8319$ & 0.9529 \\
\hline
\end{tabular}

MC- moisture content, $\mathrm{Vt}$-Terminal velocity and $\mathrm{C}_{\mathrm{d}}$ - drag coefficient

The results of measured mean terminal velocity $(\mathrm{Vt})$ and calculated drag coefficient $(\mathrm{Cd})$ of the samples at 
different moisture content were given in Figure 1 and 2. By increasing moisture content, its terminal velocity was increased. This result had also proved by Equation 3 that $\mathrm{V}_{\mathrm{t}}$ has a direct relation with mass. Moisture content had significant effect $(\mathrm{p}<0.01)$ on terminal velocity (Table 3$)$. The terminal velocity of tef grain increased from 2.98 to $3.87 \mathrm{~ms}^{-1}$ as shown in Figure 1 with increasing in moisture content from $7.3 \%$ to $25.94 \%$ w.b. But on the contrary, the resulting drag coefficient related to each moisture content decreased from 0.77 to 0.59 with increasing in moisture content from $7.3 \%$ to $25.94 \%$ Figure 2.

As shown in table 2 there are no significant pairwise differences among the means of drag coefficient in as moisture content increase from 7.3 to $10.46 \%$. Regarding to terminal velocity there is significant difference at probability level of 5\% as moisture content increasing from 7.3 to $25.94 \%$.

Table 2. LSD-Pairwise Comparisons result of drag coefficient and terminal velocity

\begin{tabular}{|l|l|l|}
\hline Parameters & Drag coefficient & Terminal velocity \\
\hline 7.3 & $0.7733 \mathrm{a}$ & $2.9700 \mathrm{e}$ \\
10.46 & $0.6800 \mathrm{ab}$ & $3.2100 \mathrm{~d}$ \\
14.62 & $0.6300 \mathrm{~b}$ & $3.3133 \mathrm{c}$ \\
18.78 & $0.6167 \mathrm{~b}$ & $3.5900 \mathrm{~b}$ \\
25.94 & $0.5900 \mathrm{~b}$ & $3.8667 \mathrm{a}$ \\
\hline CV \% & $\mathbf{0 . 2 2}$ \\
Alpha $=\mathbf{0 . 0 5}$ & \\
\hline
\end{tabular}

The same letter in column no significant difference

Table 3 ANOVA Table for Drag coefficient and terminal velocity

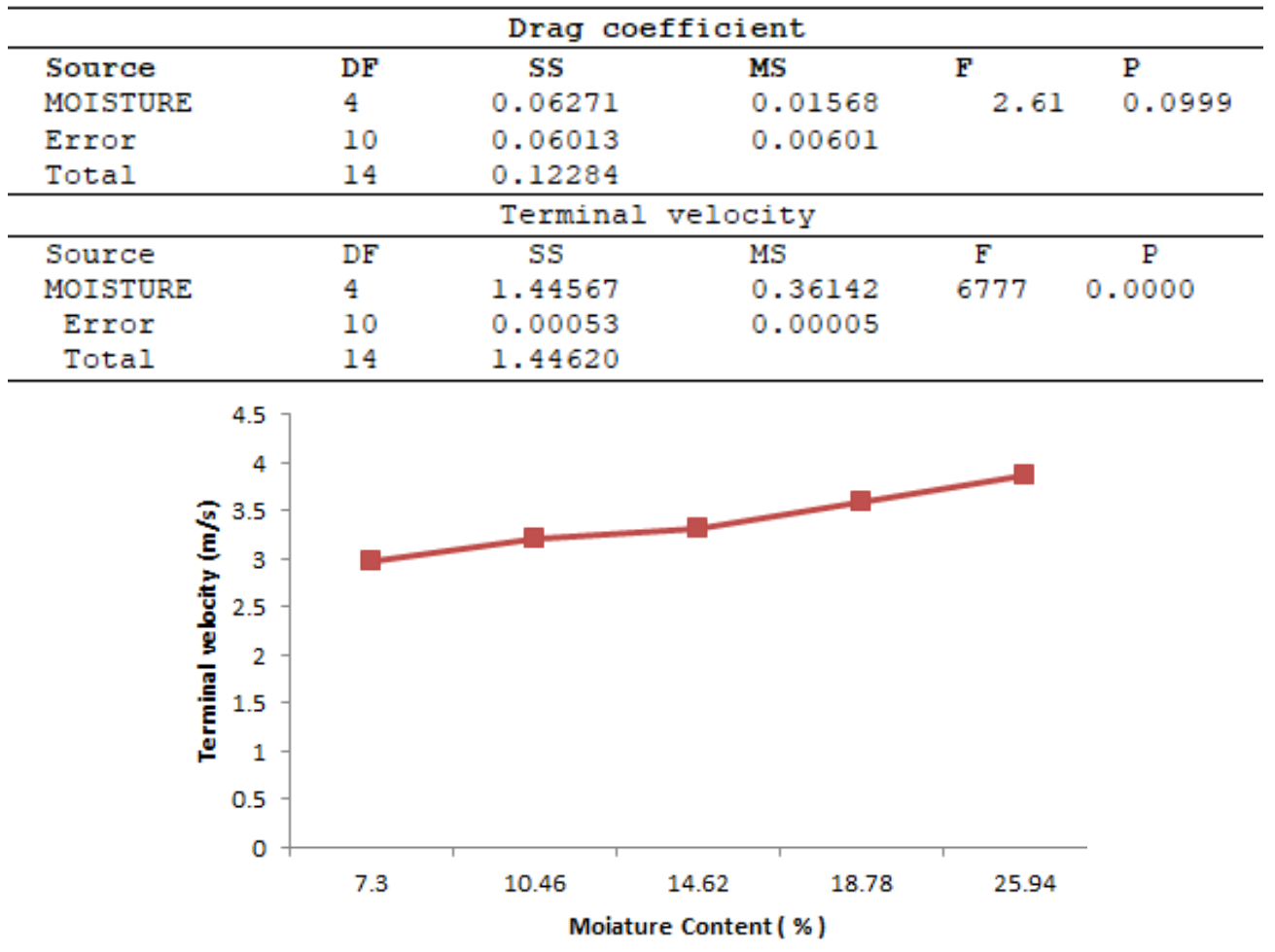

Figure 1. Effect of Moisture Content on terminal Velocity of Tef Grain 


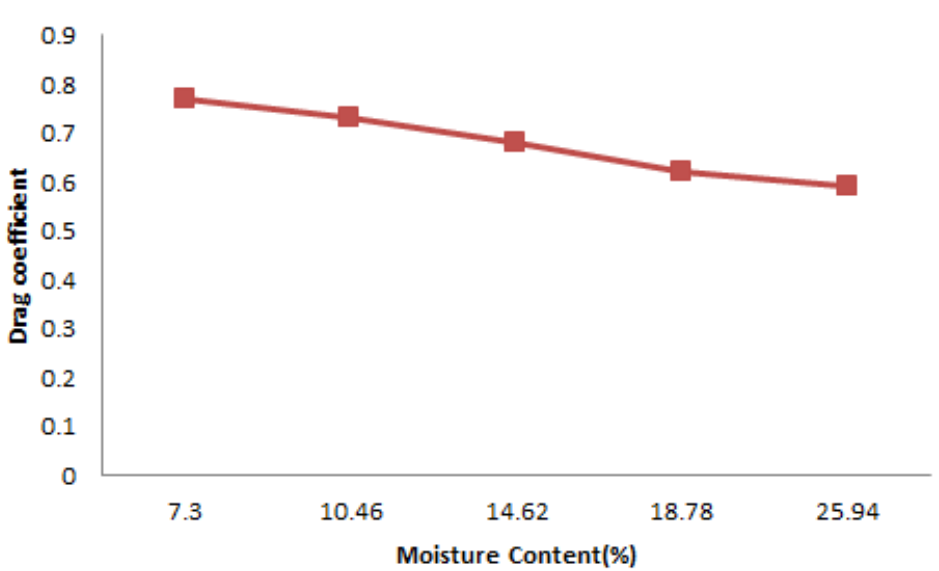

Figure 2. Effect of Moisture Content on drag coefficient of Tef Grain

The decrease in drag coefficient is related to the increase in mass and as well as increased frontal area. The range of drag coefficients indicated that the tef grain behaved ore like spheres when they had higher moisture content. There is a linear increase in terminal velocity against moisture content as was shown with various terminal velocity of tef grain in the graph. Short straws are the major contaminants of threshed materials. Zewdu, 2007 and Abduljelil, 2010, also observed the same effect with their study on the tef and straws. They are also very difficult to separate from the grain. Straws are neither symmetrical nor uniform (due to tapering), in density (due to nodes) and their lack of symmetry causes aerodynamic instability. Aerodynamic instability of tef straws was not obtained in this particular experiment conducted on the straws. The same phenomenon was seen in this experiment particularly having a pronounced effect on the end-node straws. This result was the same as found by other researchers for some other agricultural material (Khoshtaghaza and Mehdizadeh, 2006; Ayman, 2009; Shellard and Macmillan,Gubta,2006).

Terminal velocity measurements of straw materials were shown in Figure 3. Generally, end node straws showed higher terminal velocities as a result of their orientation in the vertical upright position minimizing their frontal area to the cross-section of the straws. Middle- node straws showed higher terminal velocities than nodefree straws. Assuming that straws had the symmetrical circular cross-sectional areas without tapering at one end, node-free straws could have lower weight than middle-node straws even if their diameter and length are equal with middle nodes.

Under the assumption that both straws lie horizontally with maximum frontal area, this value should yield in lower terminal velocities in node-free straws. The terminal velocity node-free and middle node straws of tef showed a decrease from 3.61 to $2.19 \mathrm{~m} / \mathrm{s}$ and 3.12 to $2.76 \mathrm{~m} / \mathrm{s}$ however, for end-node straw an increase in terminal velocity 3.51 to $5.58 \mathrm{~m} / \mathrm{s}$ with an increase in length of straw from 1 to $10 \mathrm{~cm}$ was seen Figure 3 .

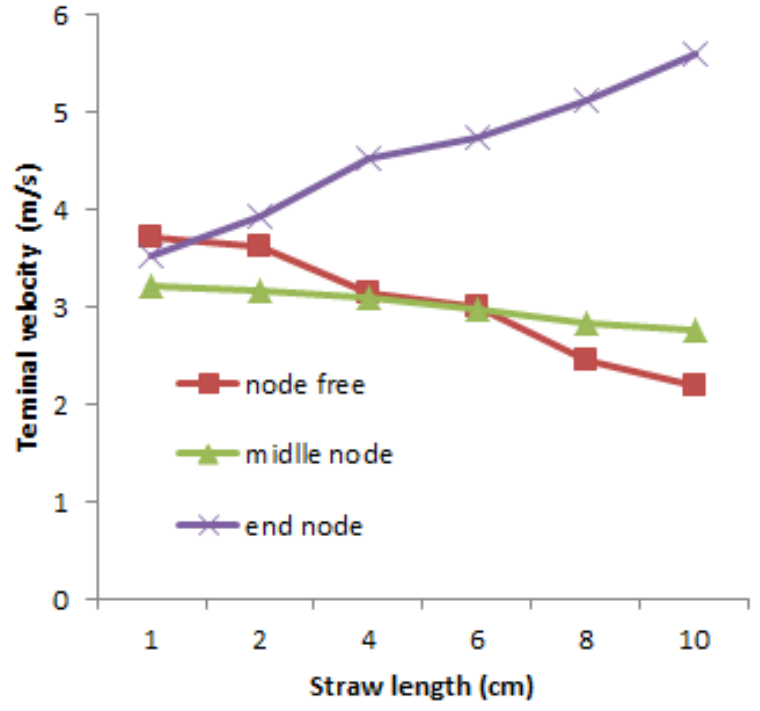

Figure 3. Effect node position and varying of straw on terminal velocity of tef straw 
Table 4. Measured tef grain terminal velocity by different researchers at different moisture contents

\begin{tabular}{|l|l|l|l|}
\hline Researcher & Tef variety & Moisture content & Terminal velocity \\
\hline Zewdu, 2007 & - & $6.5-30.1 \%$ & $3.08-3.96 \mathrm{~m} / \mathrm{s}$ \\
Abduljelil, 2010 & Dz Cr-196 & $11.94-27.1 \%$ & $3.24-4.04 \mathrm{~m} / \mathrm{s}$ \\
\hline
\end{tabular}

\section{Conclusion and Recommendation}

The following conclusions can be drawn from the experiments:

1. By increasing the moisture content from 7.3 to $25.94 \%$ (w.b.), its terminal velocity increased linearly from 2.98 to $3.87 \mathrm{~m} / \mathrm{s}$.

2. Terminal velocity of tef straw depended on node position and end node position had the highest terminal velocity.

3. The Terminal velocities of end nodes exhibited gradual increase. The highest Terminal velocities were obtained from end node straws.

4. Because the minimum terminal velocity of tef samples was $2.98 \mathrm{~m} / \mathrm{s}$ and the maximum terminal velocity of tef straws at end node was $5.58 \mathrm{~m} / \mathrm{s}$ so complete separation tef grain from straw is impossible.

5. The drag coefficient of tef seed decreased with increase in moisture content.

\section{Reference}

Abduljelil Mohammed, 2010. Investigation into Tef Grain, Straw and Chaff Mixture Separation and Cleaning. Unpublished MSc.Thesis. Adama University, Adama, Ethiopia.

Ayman Hafiz Amer Eissa,2009. Aerodynamic and solid flow properties for flaxseeds for pneumatic separation by using air stream. Int J Agric \& Biol Eng Open Access at http://www.ijabe.org Vol. 2 No.4 31

Balasubramanian D (2001). Physical properties of raw cashew nut. Journal of Agricultural Engineering Research, 78(3), 291-297, doi:10.1006/jaer.2000.0603

Bekabil Fufa, Befekadu Behute, Rubert Simons and Tareke Berhe, 2011. Strengthening the Tef Value Chain in Ethiopia. Ethiopian Agricultural Transformation Agency (EATA). Addis Ababa, Ethiopia

Dursun E; Dursun I (2005). Some physical properties of caper seed. Biosystems Engineering, 92(2), 237-245, doi:10.1016/ j.biosystemseng.2005.06.003

Eleni Zaude, 2001. Market Institutions, Transaction Costs and Social Capital in the Ethiopian Grain Market. International Food Policy Research Institute. Washington, DC. USA.

Gorial, B.Y. and J.R. O’Callaghan. 1990. Aerodynamic properties of grain/straw materials. Journal of Agricultural Engineering Research 46:275-290.

Gupta R K; Arora G; Sharma R (2006). Aerodynamic properties ofsunflower seed (Helianthus annus L.) Journal of Food Engineering, doi:10.1016/j.jfoodeng.2006.03.010.

M. Khoshtaghaza and R. Mehdizadeh. "Aerodynamic Properties of Wheat Kernel and Straw Materials". Agricultural Engineering International: the CIGR Ejournal. Manuscript FP 05 007. Vol. VIII. March, 2006.

M. Kara, S. Bastaban, I. Öztürk, F. Kalkan, and C. Yildiz, 2012. Moisture-dependent frictional and aerodynamic properties of safflower seeds. Int. Agrophys., 2012, 26, 203-20.ers, New York, USA.

Mohsenin, N.N., 1978. Physical Properties of Plant and Animal Materials. Gordon Breach Science puplish

Rabbani, H., M. Behroozilar, S. Mohtasebi and A. Gerami, 2002. Aerodynamic properties of chick pea. Ph. D Thesis, Tehran University, Tehran, Iran

Shellard, J.E. and R.H. Macmillan. 1978. Aerodynamic properties of threshed wheat materials. Journal of Agricultural Engineering Research 23: 273-281

Simonyan, K.J., Y.Yiljep and O.Mudiare, 2006. Modeling the Cleaning Process of a Stationary Sorghum Thresher. Agricultural Engineering International: the CIGR Journal of Scientific Research and Development, Vol. 8.

Tabak, S. and D. Wolf. 1998. Aerodynamic properties of cotton seeds. Journal of Agricultural Engineering Research 70:257-265.

Tabatabaeefar, A., 2003. Moisture-dependent physical properties of wheat. Int. Agrophysics J., 17: 207-11

Zewdu Abdi, 2007. Aerodynamic properties of tef grain and straw material. Journal of Biosystems Engineering, 98(2007): 304-309.

Zewdu Abdi and Solomon. W., 2007. Moisture-Dependent Physical Properties of Tef Grain. Journal of Biosystems Engineering $96(1): 57-63$. 